Hydrology and Earth System Sciences, 6(3), 421-431 (2002) C EGS

\title{
Assessing environmental impacts on stream water quality: the use of cumulative flux and cumulative flux difference approaches to deforestation of the Hafren Forest, mid-Wales
}

\author{
Colin Neal \\ Centre for Ecology and Hydrology, Crowmarsh Gifford, Wallingford, OX10 8BB, UK \\ Email: cn@ceh.ac.uk
}

\begin{abstract}
A method for examining the impacts of disturbance on stream water quality based on paired catchment "control" and "response" water quality time series is described in relation to diagrams of cumulative flux and cumulative flux difference. The paper describes the equations used and illustrates the patterns expected for idealised flux changes followed by an application to stream water quality data for a spruce forested catchment, the Hore, subjected to clear fell. The water quality determinands examined are sodium, chloride, nitrate, calcium and acid neutralisation capacity. The anticipated effects of felling are shown in relation to reduction in mist capture and nitrate release with felling as well as to the influence of weathering and cation exchange mechanisms, but in a much clearer way than observed previously using other approaches.
\end{abstract}

Keywords: Plynlimon, stream, Hore, acid neutralisation capacity, calcium, chloride, nitrate, sodium, cumulative flux, flux

\section{Introduction}

Within the environmental sciences, there are major management issues over the impact of man on the water quality functioning of river systems. For example, within the lowlands, point and diffuse pollution from industrial, urban and agricultural sources affect riverine ecology by direct poisoning of the environment or by secondary processes such as the development of toxic algal blooms (Neal et al., 1997a). Assessing the changes occurring is often difficult because of the complexity of the processes involved and the erratic way in which nature often operates. For example, the water quality of a stream can vary over time due to changing hydrological and biological factors and the confounding influence of climate change and climate instability. This feature is seen especially in the UK uplands where there are issues of land use change, atmospheric pollution and stream acidification (Neal et al., 1997a, 2001).

Many hydrochemical, statistical and modelling approaches have been used to address the various environmental issues in relation to both concentration and flux as a starting point for assessing current change within the context of environmental management (e.g. Cooper and Evans, 2001; Cooper and Watts, 2002; Littlewood et al., 1998; Whitehead and Neal, 1987; MacNally and Hart, 1997; Lees, 1995; Whitehead et al., 2002). In this paper, the salient features of cumulative flux (CF) and cumulative flux differences ( $\ddot{\mathrm{CF}}$ ) diagrams are presented. These diagrams offer new insights into the changes occurring. The CF and ÄCF methodologies are illustrated by their application to a study of the effects of conifer deforestation of an acidic and acid sensitive upland area (Plynlimon, mid-Wales; Neal et al., 1992a,b, 1997b). The study choice is a daunting one as the catchment of concern is highly dynamic in relation to water quality at a very wide range of scales (daily events, seasonal fluctuations, decadal and longer term changes) and patterns of response to felling are difficult to observe (Neal et al., 1992a,b).

The paper serves four functions. Firstly, the salient points of the approach are described to clarify what is shown by the patterns of flux change. Secondly, the utility of the approach is illustrated by a practical example of an issue of strategic environmental concern for the UK uplands (the 
sustainability of upland UK forestry and the effects of forest rotation cycles on stream water quality; Hudson et al., 1997a; Neal et al., 1998a,b). Thirdly, the paper provides a basis for more detailed and incisive analysis of the extensive Plynlimon data record. Fourthly, the paper flags the potential value of the approach to encourage a wider use and stimulate methodological development based on stronger statistical and modelling frameworks.

\section{Study area, sampling and analysis}

The study relates to runoff chemistry for a headwater tributary stream of the River Severn in mid-Wales, the Afon Hore, which drains, in part, the Hafren Forest (Neal et al., 1997b). There are two long-term water quality and flow monitoring sites on the Afon Hore, one upstream and the other downstream of an area set for felling. In this paper, these sites are termed the upper Afon Hore and the lower Afon Hore, respectively. The Hore catchment has an area of about $3.17 \mathrm{~km}^{2}$ and an altitude range of about 360 to $470 \mathrm{~m}$ above sea level. The upper monitoring point represents the upper half of the catchment while the lower monitoring point, being near its confluence with the main tributary of the upper River Severn, the Afon Hafren, represents the Hore catchment as a whole (location map given in Neal et al., 1997b). Rainfall averages about $2500 \mathrm{~mm} \mathrm{yr}^{-1}$ and, with an evaporation loss typically of about $600 \mathrm{~mm} \mathrm{yr}^{-1}$, runoff is about $1900 \mathrm{~mm} \mathrm{yr}^{-1}$ (Hudson et al., 1997b). Runoff is "flashy": there is a rapid response to rainfall and flows vary between 0 and 4.5 cumecs.

Catchment bedrock features fractured Lower Palaeozoic mudstones, shales and grits that are overlain with thin acidic and acid sensitive soils. The upper quarter of the catchment is a hilltop plateau region dominated by acid moorland and the lower three quarters of the catchment has conifer plantation cover (mainly Sitka spruce, Picea sitchensis planted in various phases from the mid 1940s through to the late 1960s). The upper Afon Hafren catchment is about $50 \%$ forested while, prior to felling, the lower catchment was about $77 \%$ forested. The forest area downstream of the upper Afon Hore monitoring point was clear felled from 1985 to 1989.

Monitoring of the lower and upper Afon Hore began in May 1983 and in September 1984, respectively. Details of the sampling, filtration and analytical chemistry methodologies are provided in Neal et al. (1997b).

While flow data are available for the lower Afon Hore, for the full period of monitoring, flow data for the upper Afon Hore was not available for the first year of monitoring. Data infilling for flow was therefore required for the early part of the record to cover fully the information for pre-fell times. Flow data for the lower Afon Hore was used for this purpose. This is reasonable as the flow data are expressed on an aerially weighted basis $\left(\mathrm{mm} 15 \mathrm{~min}^{-1}\right)$ and flow data collected when both flumes were operative show strong linear correlations with near zero intercept and slope of unity:

Flow $_{\text {lower Hore }}=(0.984 \pm 0.014) *$ Flow $_{\text {upper Hore }}+(0.004 \pm 0.040)$.

This regression equation covers the full monitoring period, $\mathrm{r}^{2}=0.960$ and $\mathrm{N}=826$ while the \pm term represents twice the standard error.

The Hore database contains both weekly and some "opportunistic" events sampled to characterise more fully the water quality at high flows. However, as Cooper and Watts (2002) show, inclusion of such opportunistic samples can lead to significant bias in the estimation of flux with certain methodologies and bias might well occur within the present study. Because of this, the opportunistic samples are not included within the analysis.

Occasional data outliers were rarely detected when the time series information was plotted (less than $0.1 \%$ of the values). These occasional outliers primarily correspond with transcription errors. For the analysis, the outlier data was corrected in the case of clear transcription errors or rejected where contamination was evident.

\section{Cumulative flux and cumulative flux differences methodologies}

\section{GENERAL}

For the present study, the database used for analysis comprises a time series of chemical and flow data for paired response and control sites sampled at approximately the same time each week. Two approaches are taken here. One approach involves examining time series of the cumulative flux data for the response and control information on the same diagram. The other involves the examination of a time series plot of the difference in the cumulative fluxes for the response and the control. To achieve these ends, three steps are involved.

Firstly, the cumulative flux is calculated for the response and control data. This is done by applying, for a particular determinand "c", the equation

$$
\mathrm{CF}_{\mathrm{n}}={ }^{\mathrm{n}} \Sigma \mathrm{A} * \mathrm{c}_{\mathrm{n}} * \mathrm{f}_{\mathrm{n}} *\left(\mathrm{t}_{\mathrm{n}}-\mathrm{t}_{\mathrm{n}-1}\right)
$$

For this equation,

- $\quad \mathrm{CF}_{\mathrm{n}}$ is the cumulative flux up to sampling number 
"n" from time $\mathrm{t}_{0}$.

- $\mathrm{c}_{\mathrm{n}}$ is the concentration of "c" for the nth sampling point.

- $\mathrm{f}_{\mathrm{n}}$ is the flow at the $\mathrm{nth}$ sampling point.

- $\mathrm{t}_{\mathrm{n}}$ and $\mathrm{t}_{\mathrm{n}-1}$ represent the times for the $\mathrm{n}^{\text {th }}$ sampling point and the previous, $\mathrm{n}-1^{\text {th }}$, sampling point, respectively.

- "A" represents a conversion factor used to standardise units.

For the first sampling point $n=1, t_{n-1}$ must be defined outside the times given in the dataset as no sample is collected at this time. $t_{1}-t_{0}$ is taken here as the average sampling interval (in this case, seven days).

The value of "A" relates to the units of concentration, flow and the timing interval used. For example, it is calculated on the basis that flow has units of $\mathrm{mm} 15 \mathrm{~min}^{-1}$, concentration has units of $\mathrm{mg} \mathrm{l}^{-1}$ and time has units of days while flux is calculated in units of $\mathrm{kg} \mathrm{ha}^{-1} \mathrm{day}^{-1}$. Concentrations are not defined uniquely for determinands that are present in molecular form. For example, nitrate can be defined in terms of nitrate or nitrate-N (i.e. $\mathrm{mgNO}_{3} \mathrm{l}^{-1}$ or $\mathrm{mgNO}_{3}-\mathrm{N}^{-1}$ ). Thus, concentrations may be defined in terms of the molecular or the atomic weight of the component of interest in the molecule (in this case only the nitrogen making up the nitrate molecule). For molecules with molecular weight " $\mathrm{M}_{\mathrm{m}}$ " and with an atomic weight of " $\mathrm{M}_{\mathrm{a}}$ " for the element of interest, the concentration as defined in molecular terms is reduced proportionately by the ratio $\mathrm{M}_{\mathrm{a}} / \mathrm{M}_{\mathrm{m}}$ to give the concentration in atomic terms. For example, $100 \mathrm{mgSO}_{4} \mathrm{l}^{-1}$ is $100^{*}(32 / 96)=33.3 \mathrm{mgSO}_{4}-\mathrm{S} \mathrm{l}^{-1}$. In this case, atomic rather than molecular weights are used and hence $\mathrm{A}=0.96 *\left(\mathrm{M}_{\mathrm{a}} / \mathrm{M}_{\mathrm{m}}\right)$.

Secondly, the change in the cumulative flux $(\triangle \mathrm{CF})$ is estimated as the difference between the response and the control. As with any catchment experiment, there are often small differences in concentration across sites even without a response disturbance: it is advisable to normalise for this difference, given information on the concentrations for the different sites, since cumulative errors in the calculated flux difference will grow as " $n$ " increases. In the present case, the normalised flux for the control has been determined primarily by a scaling process in relation to the ratio of the flow-weighted average concentrations of the response and the control using the equation

$$
\Delta \mathrm{CF}_{\mathrm{n}}=\mathrm{CF}_{\text {n-response }}-\left[\mathrm{CF}_{\mathrm{n} \text {-control }} * \mathrm{c}_{\mathrm{fp}} / \mathrm{c}_{\mathrm{cp}}\right] .
$$

For this equation, $c_{\mathrm{fp}}$ is the average flow weighted concentration for the response site prior to disturbance (September 1984 to June 1985) for the weekly data record and $\mathrm{c}_{\mathrm{cp}}$ is the average flow weighted concentration for the control site for the same period. The equation has been used for chemical determinands that have values consistently above zero (e.g. the major anions and cations, the nutrients and trace elements). In contrast, determinands that can have both positive and negative values need to be treated differently as the flow-weighted means can produce $\mathrm{c}_{\mathrm{fp}} / \mathrm{c}_{\mathrm{cp}}$ ratios that are very large, very small, or negative even though the individual values for the response and the control are similar. This second group is exceptional, but it contains two important determinands alkalinity and acid neutralisation capacity (ANC). In the present study, $\mathrm{c}_{\mathrm{fp}}$ and $\mathrm{c}_{\mathrm{cp}}$ differ by less than $40 \%$ for the normal case while for ANC the values differ by over $300 \%$ (alkalinity is not considered in this paper). For ANC, the control data are normalised $\left(\mathrm{ANC}_{\text {normalised }}\right)$ using a regression equation between the response and the control for the period prior to disturbance. The regression equation is

$$
\begin{aligned}
& \mathrm{ANC}_{\text {normalised }}=0.97 * \mathrm{ANC}_{\text {control }}+0.3 \\
& \mathrm{R}^{2}=0.645 \text { and } \mathrm{N}=42 . \text { Thus: } \\
& \Delta \mathrm{CF}_{\mathrm{n}}=\mathrm{CF}_{\text {n-response }}-\left[0.97 * \mathrm{ANC}_{\mathrm{n} \text {-control }}+0.3\right]
\end{aligned}
$$

For both alkalinity and ANC, the flux must be described in terms of equivalents rather than weight. The unit used here is $\mathrm{kEq} \mathrm{ha}^{-1} \mathrm{day}^{-1}$.

Thirdly, time series plots of CF for the felled and the control catchment are plotted on the same graph to show the deviations in flux. Time series of $\Delta \mathrm{CF}_{\mathrm{n}}$ shows the fine details of change.

\section{CUMULATIVE FLUX AND FLUX-CHANGE TIME- SERIES PATTERNS: A SIMPLIFIED \\ REPRESENTATION.}

To show the general features of the cumulative flux and cumulative flux difference time series, consider a simple case where the flux over time for a control site is constant and the response is a simple step change where flux increases or decreases by a set amount for a fixed time and then returns to the control value. This is illustrated in the left hand side set of graphs in Fig. 1 where flux is plotted for 30 fixed time interval data points. In this figure, the response is shown for the times 5 to 10 inclusive. The figure shows three lines.

1. A horizontal line of flux 10 units time ${ }^{-1}$, from time 1 to time 30. This represents the control.

2. A horizontal line from times 1 to 5 of flux 10 units time $^{-1}$, with a vertical increase at time 5 to a flux of 15 units time ${ }^{-1}$. This line then remains horizontal at flux 


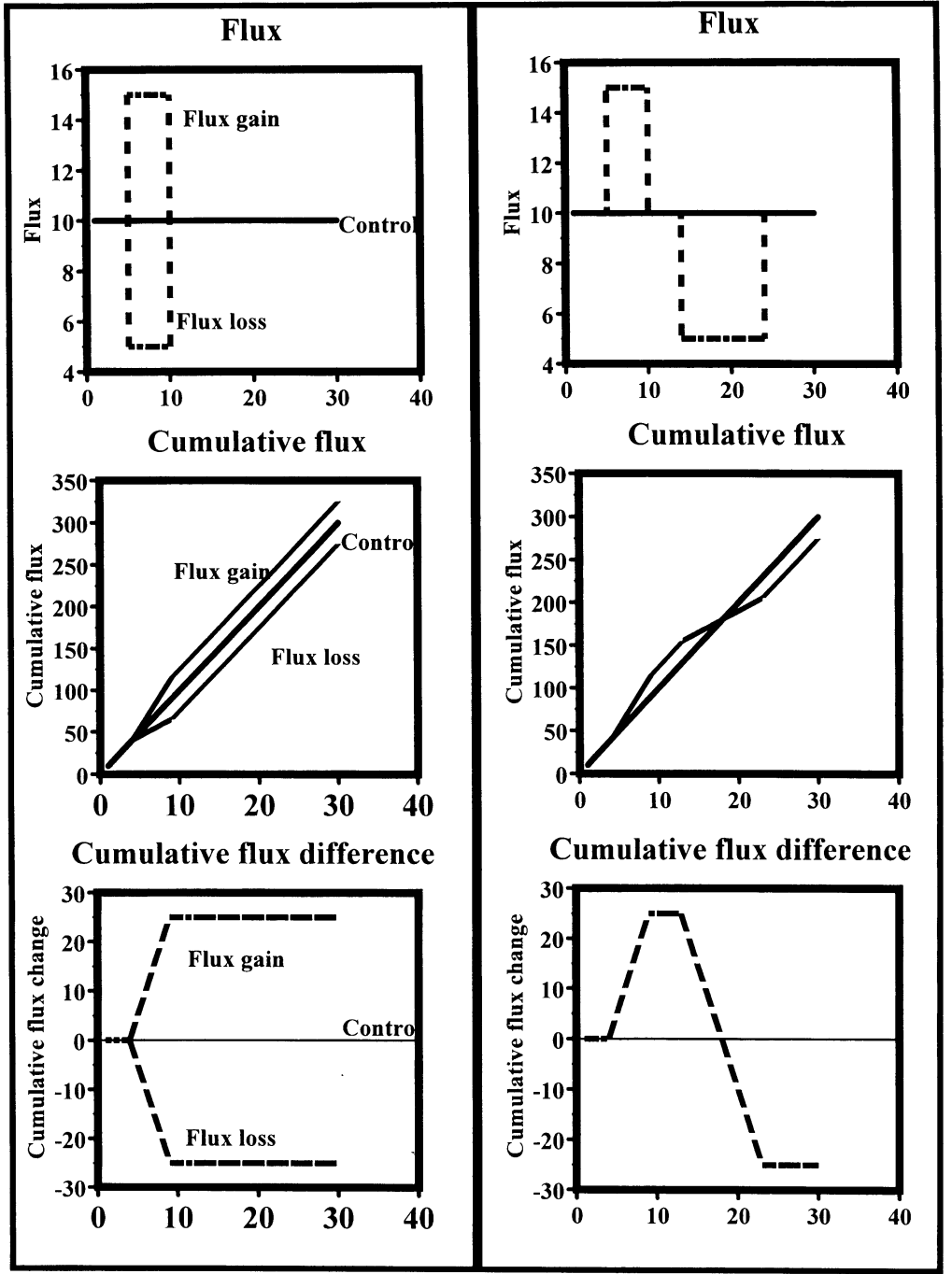

Fig. 1. A schematic of the effects of stepwise flux changes on CF and $\triangle C F$ time series.

15 units time ${ }^{-1}$ and then decreases at time 10 to a flux of 10 units time ${ }^{-1}$. Thereafter, the flux remains constant at 10 units time ${ }^{-1}$ up to the closing interval of time 30 . This will be referred to as the "step flux gain response".

3. A horizontal line from times 1 to 5 of flux 10 units time $e^{-1}$, with a vertical decrease at time 5 to a flux of 5 units time ${ }^{-1}$. This line then remains horizontal until at time 10 when it immediately increases to a flux of 10 units time ${ }^{-1}$. Thereafter, the flux remains constant at 10 units time $e^{-1}$ up to the closing interval of time 30 . This will be referred to as the "step flux loss response".

The corresponding CF diagram is shown to the middle left of Fig. 1. It also shows three lines that correspond to those in the top left hand diagram.

1. A single straight line. This is the control and the gradient is 10 units time ${ }^{-1}$, the value of the control flux.

2. A straight line, the same as the control response up to time 5, followed by an adjoining straight line of higher gradient in the time interval 5 to 10 . This is then followed by an adjoining straight line that parallels the control response line up to the closing interval of time 30 . The gradient of the line varies with the time interval. From time 1 to 5 , the gradient is 10 units time ${ }^{-1}$ and this corresponds to the control flux. From time 5 to 10, the gradient has a value of 15 units time $e^{-1}$, the value of the gain response flux. From time interval 10 to 30, the flux has a value of 10 units time ${ }^{-1}$, the value of the control flux.

3. A straight line, the same as the control response up to time 5, followed by an adjoining straight line of lower gradient in the time interval 5 to 10 . This is then followed by an adjoining straight line that parallels the 
control response line up to the closing interval of time 30. From time 1 to 5 , the gradient is 10 units time ${ }^{-1}$, this equals the control flux, and from time 5 to 10 the gradient is 5 units time ${ }^{-1}$, the value of the loss response flux. From time interval 10 to 30 , the gradient is 10 units time ${ }^{-1}$, the value of the control flux.

There are several points to note from the information on the cumulative flux diagram.

- An increase in response flux relative to the control is marked by a deviation of data to points above the control line.

- A decrease in response flux relative to the control is marked by a deviation of data to points below the control line.

- For a time interval where the response flux equals the control flux, the plotted data lie either on the same straight line or on lines parallel to each other.

- When the response flux differs from the control response, the gradients of the line differ. The gradient is higher for the response flux if there is an increase in the response flux and the gradient is lower if there is a decrease in the response flux.

- The gradient of the straight lines within a particular time interval equals the flux within that time interval.

The cumulative flux difference $(\Delta \mathrm{CF})$ time series is shown at the bottom left hand corner of Fig. 1. The graph comprises three lines and the characteristics of these three lines are as follows:

1. The control is represented by a straight line with cumulative flux change of zero for times 1 to 30 .

2. The flux gain response is marked by three regions. Firstly, for the period before the flux changes (times 1 to 5), $\Delta \mathrm{CF}=0$. Secondly, $\Delta \mathrm{CF}$ increases linearly with a gradient equal to the difference between the fluxresponse and flux-control (i.e. in this case $15-10=5$ units time $\mathrm{e}^{-1}$ ) during the period of flux gain (times 5 to 10). Thirdly, after the flux gain is over (times 10 to 30 ), $\Delta C F$ remains constant at a value of 25 units. This value equals the cumulative flux change (i.e. 5 time steps with each time step having a constant flux gain of 5 units time $^{-1}$ ).

3. The flux loss response is marked by three regions. Firstly, for times 1 to 5 , when the flux first changes, $\Delta \mathrm{CF}=0$. Secondly, during the period of flux loss (times 5 to 10$), \Delta \mathrm{CF}$ decreases linearly with a gradient equal to the difference between the flux-response and fluxcontrol (i.e. in this case $5-10=-5$ units time ${ }^{-1}$ ). After the flux-gain is over (times 10 to 30 ), $\Delta \mathrm{CF}$ remains constant at a value of -25 units. This value equals the cumulative flux change (i.e. 5 time steps with each time step having a constant flux gain of -5 units time ${ }^{-1}$ ).

Hence, information contained within the $\Delta \mathrm{CF}$ time series allows a clear indication of

- When response fluxes are or are not occurring.

- The sizes of the flux change over particular time steps (the gradient of the line).

- The integrated flux change response, relative to the control. This corresponds to the maximum/minimum value on the " $y$ " axis of the $\Delta$ CF diagram.

\section{CUMULATIVE FLUX AND FLUX-CHANGE TIME-} SERIES PATTERNS: REPRESENTATIONS THAT ARE MORE COMPLEX.

In practice, the situation will be much more complex than that described above. For example, there are issues of

- Temporal changes in control and responses in relation to seasonal variations (in the case of the nutrients) and the influence of hydrology in changing both flow and concentration (for most chemicals of interest).

- Control and response sites not being sampled at the same time of day due to the length of time taken to go from one site to the next. Thus, for hydrologically "flashy" catchments, the fluxes may be quite different on the specific day of sampling.

- Sampling of extreme events for the response and the control sites may be missed due to the infrequency of sampling relative to the duration and frequency of such events. This is particularly important in hydrologically "flashy" catchments.

- Flow and concentration measurement errors will influence the flux estimate.

Dealing with these points requires specialist treatment using long-term and highly detailed monitoring data, the use of "synthetic"/modelled time series data and detailed statistical approaches (Littlewood, 1992; Littlewood et al., 1998; Webb et al., 2000; Cooper and Evans, 2002; Cooper and Watts, 2002). The reader nonetheless needs to be aware of the issues. For this presentation, the method is to be judged in the first instance with the "sensibility" of its application to a real dataset.

Before proceeding further, it is worthwhile commenting on two aspects of complexity of relevance for explaining the patterns shown in the results section. 
Firstly, responses may not be related simply to a single gain or loss. This feature is illustrated in the three diagrams to the right hand side of Fig. 1, which are analogous to those on the left hand side of the page. They illustrate a situation where there is an initial flux gain of five units time ${ }^{-1}$ relative to the control during a time-period 5 to 10 , inclusive, followed by a flux loss of 5 units time ${ }^{-1}$ relative to the control for the period 15 to 25 . The salient features are the same as those described earlier in the paper and the plots can be considered as a "compound" form of those on the left hand side of the page. The main features to be highlighted are:

- After the flux gain, there is a crossover point to a flux loss. The crossover point is where the response line crosses the control line in the CF diagram and where the response line cuts the $\mathrm{x}$-axis in the $\Delta \mathrm{CF}$ diagram. Thus, the response line does not necessarily stay to one side of the control.

- The crossover point for both the $\Delta \mathrm{CF}$ diagram represents the situation where the initial gain equals the subsequent loss.

- The reason for there being a crossover point with this particular example is that the initial flux gain (5 units for five time steps) is smaller than the subsequent flux loss (5 units for ten time steps).

- If the initial flux gain had been greater than the subsequent flux loss, there would have been no crossover point.

- The first "plateau" region on the $\Delta \mathrm{CF}$ diagram has a flux value that equals the initial flux gain and the gradient just prior to it equals the flux gain per time step.

- The difference between the second and the first plateau fluxes (i.e. $-25-25=-50$ units) equals the subsequent flux loss (i.e. -5 units times ten time steps). The gradient of the line between the two plateau regions equals the flux gain per time interval (i.e. -5 units time ${ }^{-1}$ ).

Thus, information contained within the $\Delta \mathrm{CF}$ time series allows a clear indication within a multiple response framework of

- When response fluxes are or are not occurring.

- The sizes of each flux change over a time step (the gradient of the various lines).

- The step wise flux changes (the deviations between plateau regions).

Secondly, flux changes will often vary over time. For example, the response-effect may decay over time. This means that there will not be straight-line responses and the "sharp edges" shown in Fig. 1 will be "blunted". Further, the various responses may overlap or change in other ways and this will affect the shape of the response curves. This makes the analysis more difficult. However, many of the salient features described earlier still hold but a new terminology may be needed to describe them. For example, if the "compound" diagrams shown in Fig. 1 exhibit both "blurring of the edges" and an overlap in the gain and loss responses, there would still be an initial increase followed by a subsequent decrease in $\triangle \mathrm{CF}$. The initial increase may be described in terms of an initial response and the subsequent reduction may be described in terms of a second or a "recovery" response depending upon particular circumstances. This is best illustrated with a practical example.

\section{Results and discussion}

For this presentation, five chemical determinands with different hydrochemical properties are examined to show the salient features. The choice and the reason for the choice are as follows.

Chloride. Chloride is an anion of low chemical reactivity that is derived from the atmosphere associated with rainfall, but also with mist. The concentrations of chloride in rainfall are subject to varying maritime input of sea salts. The small chloride concentration variations in the stream, relative to the atmospheric input, is attributed to physical storage and variable residence times rather than chemical interactions within the catchment (Neal and Kirchner, 2000). For chloride, the issue of concern is "can the approach being presented identify whether deforestation leads to a reduction in chloride flux?" Wilkinson et al. (1997) estimated, for the Plynlimon catchments, that mist capture of chloride by the vegetation amounts to about $38 \%$ of the deposition for the forest and $13 \%$ of the deposition for low lying vegetation (moorland cover). Deforestation of the Hore catchment should therefore reduce chloride deposition to an intermediate value as only half of the catchment has been felled.

Sodium. Sodium is a cation that is also derived mainly from the atmosphere and it is damped in the stream relative to the atmospheric input. However, unlike chloride, cation exchange occurs with exchange sites in the soil. This process can lead to attenuation of the sodium signal relative to chloride and the variations in sodium are usually even more damped than chloride (Neal and Kirchner, 2000). With felling, sodium flux should be reduced like chloride as it too is captured by the vegetation in significant amounts and 
to different degrees by different vegetation (Wilkinson et al., 2000, provided estimates of 40 and $14 \%$ for forest and moorland, respectively, at Plynlimon). Thus, while sodium flux, like that of chloride, might decline, there is also the possibility of increased sodium release because nitric acid generation following felling leads to displacement of sodium from the soil exchanger by hydrogen ions. The issue linkage for sodium with this paper is "can these effects be seen? Is the scale of the reduction of mist inputs as anticipated?"

Nitrate. Nitrate release with deforestation represents one of the major changes in water quality (Neal et al., 1998a, b). The disruption of the biological cycle by felling leads to increased microbial decomposition as well as reduced uptake by the growing vegetation. As new vegetation becomes establishes after felling, the nitrate surge decreases. The issue for this paper is "can the flux change be gauged?"

Calcium. Calcium comes mainly from weathering of the bedrock. Calcium also occurs on cation exchange sites within the soil. Further, calcium is taken up by the developing biomass following felling. The effect of deforestation on this component is unclear. Analysis of this aspect charts new territory.

Acid Neutralisation Capacity (ANC). ANC is the fundamental measure of surface water acidification. ANC is the difference between the strong base cations $(\mathrm{Na}+\mathrm{K}+$ $\mathrm{Ca}+\mathrm{Mg})$ minus the sum of the strong acid anions $(\mathrm{Cl}+$ $\mathrm{NO}_{3}+\mathrm{SO}_{4}$ ) and is expressed on a micro equivalent per litre basis. Positive ANC corresponds to waters which are of low acidity ( $\mathrm{pH}$ typically greater than six) while negative ANC corresponds to acidic waters which are often aluminium bearing. The cut-off between positive and negative ANC approximates the divide between healthy and acid-impacted stream ecology. ANC would be expected to decrease for the period where nitrate generation is increased due to felling (i.e. ANC becomes either less positive or more negative in value) and then to recover as the nitrate concentrations recede. This pattern has been observed before at Plynlimon, but only for a site, the south2Hore catchment, where the changes involved are strongly marked (Neal et al., 1998a)

The results of the exercise are presented in Figs. 2-6 for the respective components. Each of these figures comprises three graphs. The top graph of each page compares the felled and control time series overlaid. This shows both the degree of variation and the level of deviation between felled and control concentrations. The middle graph shows the cumulative flux plot and the bottom shows the cumulative flux difference. The salient features are as follows.
Chloride. Chloride concentrations vary between about 170 and $700 \mu \mathrm{M} \mathrm{l}^{-1}$ for both the felled and the control sites. Over time there seems to be a small divergence in concentration with the control having a slightly higher concentration than the response site after felling (having normalised the data prior to felling for the response and control sites). With the CF diagram, the cumulative fluxes for both the response and the control are approximately linear. However, there is a small and increasing divergence between the two lines from about the time the felling was complete in 1989: the response has lower values than the control during this period. The divergence is most clearly observed within the $\Delta C F$ diagram which shows a very small negative cumulative flux change up to about the end of the felling period and perhaps one further year (1990). Thereafter, there is a uniform negative gradient of about $-20 \mathrm{~kg} \mathrm{ha}^{-1}$. This corresponds to a flux change relative to the control of about $14.6 \%$ (double this figure if the catchment were fully forested). For a fully forested catchment, the present estimate of $29.2 \%$ fits well with an estimated change in mist capture from forest of $38 \%$ to moorland of $13 \%$. These results indicate that with deforestation, chloride capture by mist is reduced to the levels encountered in a moorland situation, for the first decade at least after felling, and that the changeover occurs soon after felling is completed.

Sodium. Sodium concentrations vary between about 50 to $450 \mu \mathrm{M} \mathrm{1}^{-1}$. Like chloride, there is some evidence of a separation between a control and the post-felling response for sodium, having normalised the pre-fell data for the response and control sites. This is indicated in the $\mathrm{CF}$ diagram and most clearly in the $\triangle \mathrm{CF}$ diagram. There are some differences for sodium compared to chloride. In the case of the CF diagram, the control and fell responses are very similar, the cumulative flux is approximately linear for both the control and the fell data and the only clear separation emerges around 1998 when the control flux is slightly higher than the fell. Around 1990 there is also a tiny separation visible but, in this case, the fell line is above the control. The $\triangle \mathrm{CF}$ diagram shows the deviations between the control and the fell more clearly. During the felling phase, the sodium flux increases until about 1990 when the flux difference declines with a return to a fell-control flux balance by around 1992. There is an approximately linear decline thereafter. The flux change involved is about $13 \%$ gain between 1987 and 1990 and a $8 \%$ loss thereafter: these figures double for complete forest cover.

The results show what would be anticipated from theory on a qualitative basis. There are two aspects to this.

1. Anion concentrations initially increase following felling 
Chloride time series
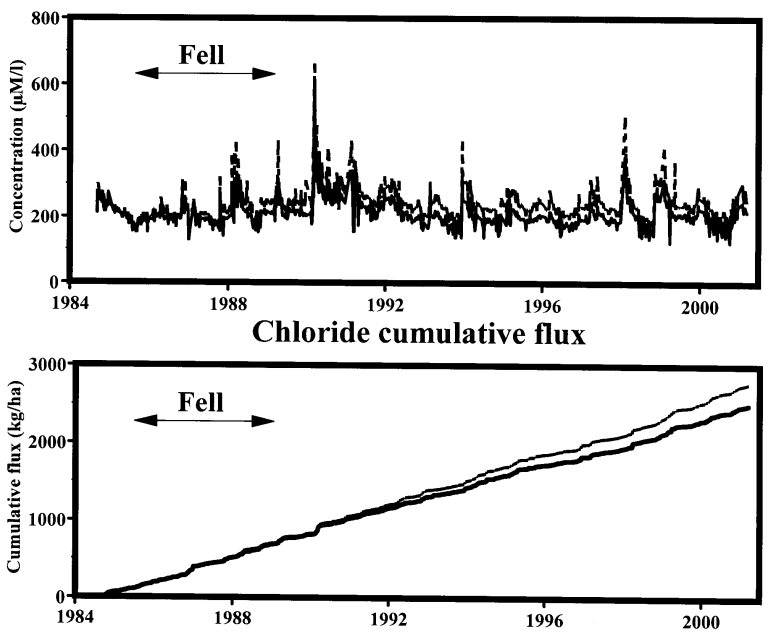

Chloride cumulative flux change

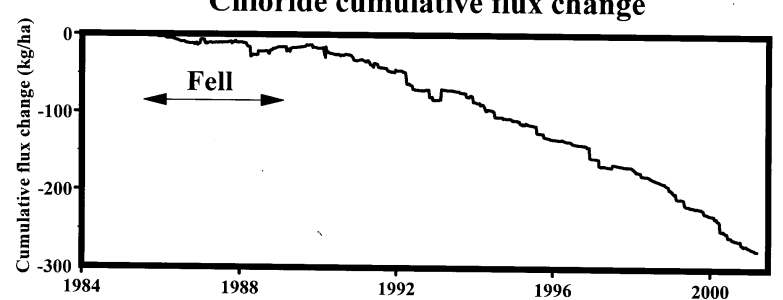

Fig. 2. Chloride concentration, $C F$ and $\triangle C F$ time series for the Afon Hore. The solid thicker line represents the fell and the thinner dashed line represents the control. Felling took place between 1985 and 1989. The graph illustrates that the chloride flux decreases with felling. Chloride essentially comes from the atmospheric deposition. Part of this deposition is associated with mist and mist capture is reduced with felling owing to the lower surface area of the vegetation.

due to nitrate generation (and some mineralisation of sulphate). The anion increase is counterbalanced by an increase in hydrogen ion, calcium and magnesium concentrations. This, in turn, leads to desorption of sodium from the exchange sites by increased competition with these other cations and hence sodium flux increases.

2. After the initial increase in the various anions and cations following felling, there is a recovery response as anion and cation concentrations decrease and the atmospheric deposition of sodium is also lowered due to a reduction of mist inputs induced by a reduction in the surface area of the vegetation. This leads naturally to a reduction in sodium flux.

Nitrate. Nitrate concentrations vary from around 20 to 340 $\mu \mathrm{M}^{-1}$ and there are clear yearly oscillations associated with yearly biological changes linked to forest nutrient requirements and microbial breakdown processes. With
Sodium time series
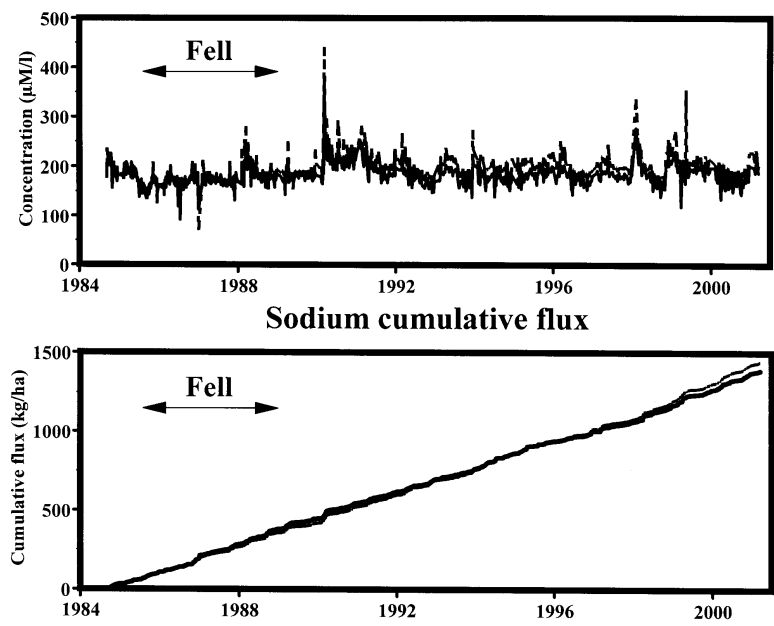

Sodium cumulative flux difference

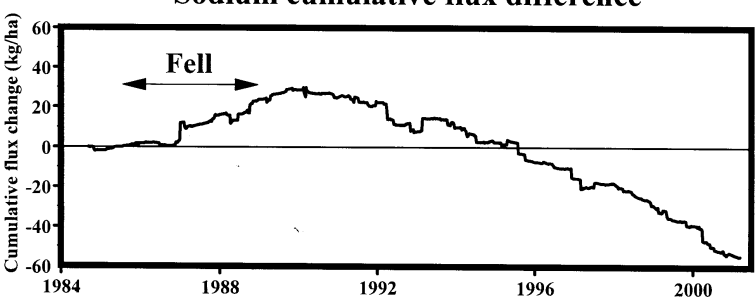

Fig. 3. Sodium concentration, $C F$ and $\triangle C F$ time series for the Afon Hore. The solid thicker line represents the fell and the thinner dashed line represents the control. Felling took place between 1985 and 1989. The graph illustrates that the sodium flux increases and then decreases with felling. Sodium essentially comes from the atmospheric deposition but sodium is also bound to cation exchange stores within the soil. The increase in concentration with felling results from an initial increase in nitrate and sulphate concentrations, which leads to release of sodium from cation exchange sites. The decrease in sodium concentration results from a decline in nitrate allowing re-sorption by cation exchange and sulphate concentrations coupled to a reduction in sodium deposition due to a lowering in mist capture as the surface area of the vegetation is reduced on felling.

felling, concentrations increase by a factor of two to three relative to the normalised control. This increase is maintained throughout the felling period and for a few years after felling. Gradually felling responses decline until around 1993, fell and control responses being about the same. Subsequent to this time, the situation reverses and gradually the nitrate concentrations for the control exceed that for the fell site. Around 1996, concentrations for the control and the fell site increased. This feature is observed across all the catchments (it is related to general climatic factors and it is not associated with felling; Neal et al., 2001). The CF and $\triangle \mathrm{CF}$ diagrams show the changes very clearly. In the case of the CF diagram, the control is approximated by a straight line with small curvilinear patterns superimposed while the felling response curve shows a marked deviation away from linearity. The greatest increase in flux occurs 
Nitrate time series
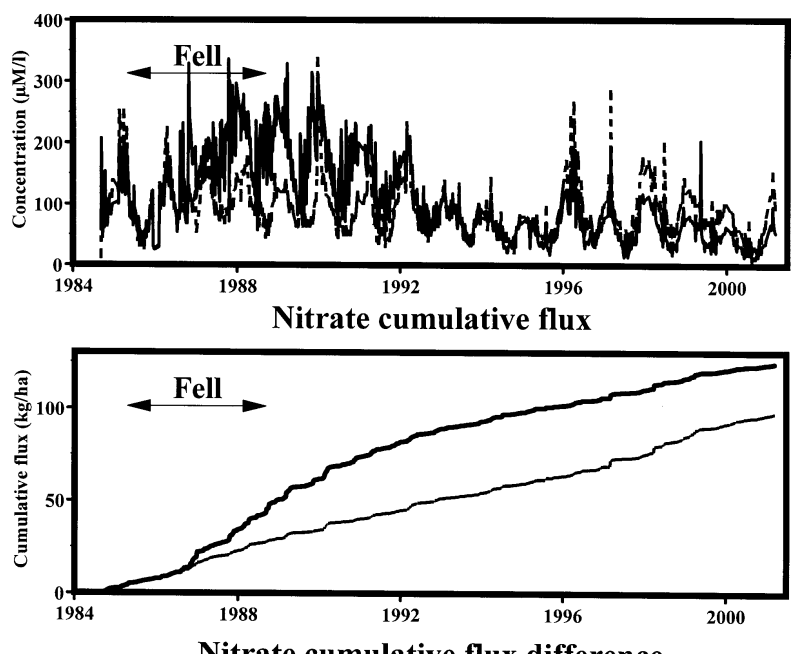

Nitrate cumulative flux difference

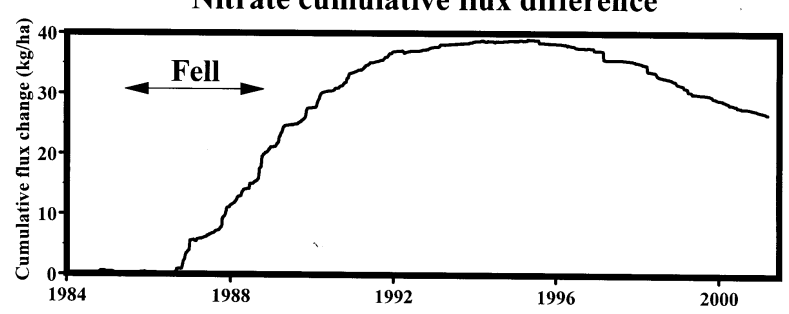

Fig. 4. Nitrate concentration, $C F$ and $\triangle C F$ time series for the Afon Hore. The solid thicker line represents the fell and the thinner dashed line represents the control. Felling took place between 1985 and 1989. Note that the flux units are in terms of $\mathrm{NO}_{3}-\mathrm{N}$. The graph shows that with felling, nitrate is initially released and then returns to levels equivalent and then levels lower than the period prior to felling. The initial increase is associated with the disruption of the biological cycle with felling which induces higher organic decomposition rates and lower uptake into the growing biomass. The subsequent reductions are associated with an increasing nitrate uptake by the vegetation as it re-establishes itself.

during the period of felling (1985 to 1989) and the flux change then flattens off by 1994: the total nitrate flux gain is about $39 \mathrm{kgNO}_{3}-\mathrm{N} \mathrm{ha}{ }^{-1}$. Then, the nitrate flux change reverses and the flux loss from the catchment declines (i.e. the response flux becomes lower than the control flux). However, the recovery is far from complete even six years after the cumulative flux difference peaks. The $\Delta \mathrm{CF}$ diagram provides a good illustration of two processes. There is an initial felling response where the disruption of the biological cycle leads to release of nitrate. This disturbance response is followed by a recovery response where the regrowth of the vegetation and nitrogen requirements are high.

Calcium. Calcium concentration varies greatly even on a week-to-week basis: the range is about 10 to $120 \mu \mathrm{M} \mathrm{l}^{-1}$. This reflects the hydrochemically dynamic character of the catchment with respect to calcium and hydrology: baseflow
Calcium time series
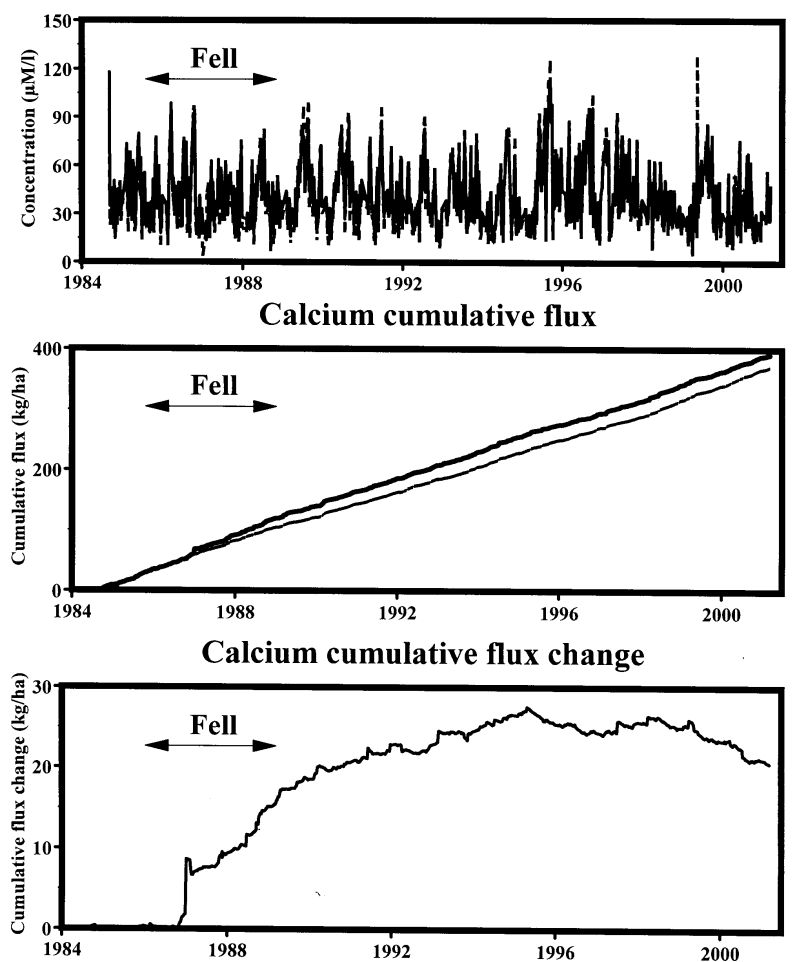

Fig. 5. Calcium concentration, $C F$ and $\triangle C F$ time series for the Afon Hore. The solid thicker line represents the fell and the thinner dashed line represents the control. Felling took place between 1985 and 1989. The results show that calcium is released from the catchment for the first few years after felling before concentrations return to those prior to felling. This increase is probably associated with increased weathering.

waters have a much higher calcium concentration than stormflow waters because a greater proportion of water comes from the lower soils and bedrock areas where weathering of calcium carbonate and calcium bearing silicates occurs (Neal et al., 1997b). Calcium seems to have the highest concentrations in the control but what happens under high flow conditions it is not clear from the concentration time series. The $\mathrm{CF}$ and $\Delta \mathrm{CF}$ diagrams show that, with felling, there is a net gain in calcium and the most rapid gain in calcium occurs during the felling period. Thereafter, the gain declines slowly to zero by around 1997. It is unclear if there is a small reduction in flux, as for nitrate, after 1997. The total flux gain is about $27 \mathrm{~kg} \mathrm{ha}^{-1}$; this corresponds to about a $9 \%$ flux gain relative to the control between 1987 and 1996 (i.e. an 18\% gain for 100\% forest). As with the previous cases, the CF diagram shows approximately straight lines for the control and the fell data although the gradients, in both cases, are slightly higher during the early period of record (1984 to 1987). 

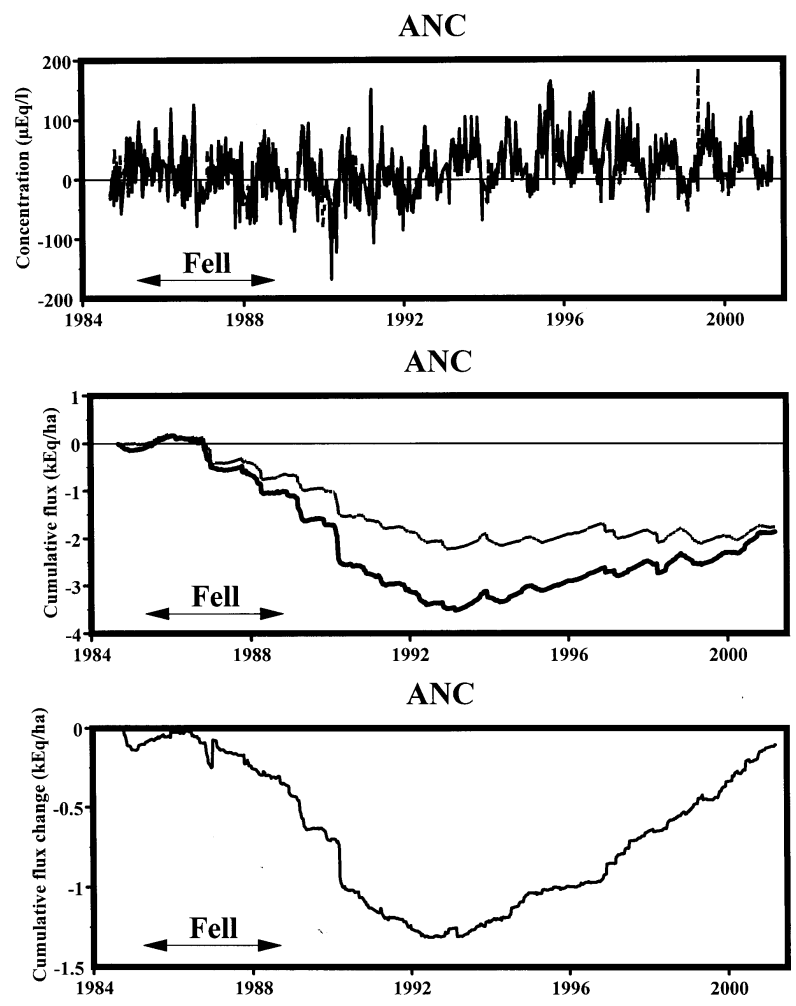

Fig. 6. ANC concentration, $C F$ and $\triangle C F$ time series for the Afon Hore. The solid thicker line represents the fell and the thinner dashed line represents the control. Felling took place between 1985 and 1989. The results show that the stream becomes more acidic initially with felling (ANC declines) as nitric acid is generated and increased anion concentrations promotes hydrogen ion displacement from cation exchange sites. The stream then shows a decline in acidity as anion concentrations are reduced due to increased uptake of nitrate into the developing biomass and reduced in mist capture.

ANC. ANC shows large variations in concentration (from about -160 to $200 \mu \mathrm{Eq}^{1^{-1}}$ ); this reflects a large flow related variation in ANC concentration for the same reason as calcium. Thus, positive ANC is associated with baseflow waters that are enriched in bicarbonate and divalent base cations released by weathering of the bedrock. Correspondingly, negative ANC is associated with stormflow conditions where stream water is supplied mainly from the acidic base-poor soils. The $\mathrm{CF}$ and $\triangle \mathrm{CF}$ diagrams show a clearer picture of the effects of felling. With felling, there is a uniform decline in ANC relative to the control until 1993 (a change of $-1.3 \mathrm{kEq} \mathrm{ha}^{-1}$ over a period of six to seven years: i.e. a $-0.2 \mathrm{kEq} \mathrm{ha}^{-1}$ year $^{-1}$ change). After 1993, there is a gradual recovery and the recovery to pre-fell conditions is almost achieved by 2001 . These patterns are almost the inverse of that observed for nitrate, as would be anticipated due to the acidifying nature of the nitrate release. However, the recovery is more marked for ANC compared to nitrate and this reflects the reduction in chloride (and sulphate) associated with reduced scavenging of the mist input. For ANC, neither the control nor the fell response show the simple linear features on the $\mathrm{CF}$ diagram that the other determinands do and this reflects the lower ANC values encountered from around 1988 to 1992 . This period of lower ANC corresponds to the time when chloride concentrations peaked in the streams and such increases would be expected to acidify the water by cation exchange reactions. With regards to the scale of ANC change, the felling response corresponds to a decrease in ANC concentration averaging $10 \mu \mathrm{Eq} \mathrm{l}^{-1}$ which cannot be resolved easily within the concentration time series: the decline would be twice this value if forest coverage had been $100 \%$. This decline is consistent with the information on felling of a small tributary of the Afon Hore (south2Hore) where the felling response amounts to a decrease of $20 \mu \mathrm{Eq} \mathrm{l^{-1 }}$ although the subsequent recovery is smaller in the case of the Afon Hore (c.f. Neal et al., 1998a).

\section{Conclusion and wider comments}

- The results presented here illustrate a valuable use for the $\mathrm{CF}$ and $\triangle \mathrm{CF}$ time series. In the form presented here, they provide a relatively straightforward analytical tool to add to those commonly used.

- This paper provides a beginning for assessing flux changes and, as described earlier in the paper, there are clearly difficulties in obtaining accurate fluxes. Statistical methods for the analysis of error terms for flux and flux change need to be developed. There are not only issues of measurement error and sampling interval, but also uncertainty as to how representative the control is and what the overall error will be. There are important methodological developments within the arena of flux estimation that must be considered within the CF and $\triangle \mathrm{CF}$ approaches (Littlewood, 1992; Littlewood et al., 1998; Cooper and Evans, 2002; Cooper and Watts, 2002). The application of a statistically based cumulative sum (cusum) approach is also worth noting. This approach has been developed by engineers and statisticians over many years. It has been used effectively and responsively mainly to monitor change in manufacturing processes but it is now being used for environmental studies (MacNally and Hart, 1997; Lees, 1995). The cusum approach has similar features to the cumulative sum difference approach $(\triangle \mathrm{CF})$ described in this paper. Indeed, the cusum approach might be better termed "cusumdifference" since the summation of differences is usually examined.

- An important, perhaps the most important development, needed to obtain reliable flux estimates, will be the use 
of additional information to produce finer scale resolution of the temporal patterns of flux change. For example, chemical-flow or chemical-temperature rating curves (or some combination) may be used to infill the chemical record given the much more detailed flow and temperature record commonly available. This is needed since, at present, it is assumed that the weekly data for flow and chemistry represent the full period between sampling times. This is certainly not true for the highly dynamic catchments being studied here or, in many cases, elsewhere.

- In the concentration time series examined other than nitrate, there is great difficulty in observing any clear changes with felling owing to the variability in the patterns observed for the response and control sites. This feature is related to factors such as short-term changes in hydrology and seasonal to decadal processes linked to climatic change.

- The concentration time series plots are important in their own right as they emphasise different features from the $\mathrm{CF}$ and $\triangle \mathrm{CF}$ time series.

- The $\mathrm{CF}$ and, in particular, the $\Delta \mathrm{CF}$ time series pick up certain detailed changes that the concentration time series cannot pick up.

- The $\mathrm{CF}$ and $\triangle \mathrm{CF}$ time series qualify some of the major processes operative. These processes include mist capture by the vegetation, cation exchange processes and chemical weathering.

- The CF and $\triangle \mathrm{CF}$ time series indicate the longevity of change in terms of both a disturbance and a recovery response. Clearly, decades of monitoring are required to pick up the full scale of the changes occurring for many of the determinands examined here. In this case, the length of record required is on the scale of the forest rotation length itself, 30 to 40 years.

- In the present study, the concentration, $\mathrm{CF}$ and $\Delta \mathrm{CF}$ time series are of direct relevance to forest management. Other than for nitrate, the results show clearly that the concentration and flux changes associated with felling are small and, after a few years, there is clear recovery of most of the determinands described here.

- In terms of forest management, the patterns described here show that the effects of felling on acidification of the streams are small but that there are potential issues of nitrate-stimulated eutrophication with felling. Indeed, the clear fell in the Hore was designed within an experimental framework to maximise the impacts. However, the current practice of felling small areas of plantation forest in a given year will minimise impacts (Neal et al., 1998a,b). These findings are consistent with other studies in the area.

\section{References}

Cooper, D.M. and Evans, C.D., 2002. Constrained multivariate trend analysis applied to water quality variables. Environmetrics, 13, 43-53.

Cooper, D.M. and Watts, C.D., 2002. A comparison of river load estimation techniques; application to dissolved organic carbon. Environmetrics. (In press).

Hudson, J.A., Gilman, K. and Calder, I., 1997a. Land use and water quality issues in the uplands with reference to the Plynlimon study. Hydrol. Earth Syst. Sci., 1, 389-397.

Hudson, J.A., Crane, S.B. and Blackie, J.R., 1997b. The Plynlimon water balance 1969-1995: the impact of forest and moorland vegetation on evaporation and streamflow in upland catchments. Hydrol. Earth Syst. Sci., 1, 409-427.

Lees, F.M., 1995. Have emission reductions led to improvements in water quality at Loch Dee in Galloway? Water Air Soil Poll., 85, 695-700.

Littlewood, I.G., 1992. Estimating contaminant loads in rivers: a review. Institute of Hydrology Report Series, 117. Institute of Hydrology, now Centre for Ecology and Hydrology (Wallingford), Crowmarsh Gifford, Wallingford, OXON, OX10 8BB, UK. 81pp.

Littlewood, I.G., Watts, C.D. and Custance, J.M., 1998. Systematic application of United Kingdom river flow and quality databases for estimating annual river mass loads (1975-1994). Sci. Tot. Environ., 251/252, 21-40.

Mac Nally, R. and Hart, B.T., 1997. Use of CUSUM methods for water-quality monitoring in storages. Environ. Sci. Tech., 31, 2114-2119.

Neal, C. and Kirchner, J.W., 2000. Sodium and chloride levels in rainfall, mist, streamwater and groundwater at the Plynlimon catchments, mid-Wales: inferences on hydrological and chemical controls. Hydrol. Earth Syst. Sci., 4, 295-310.

Neal, C., Fisher, R., Smith, C.J., Hill, S., Neal, M., Conway, T., Ryland, G.P. and Jeffrey, H.A., 1992a. The effects of tree harvesting on stream water quality at an acidic and acid sensitive spruce forested area: Plynlimon, mid-Wales. J. Hydrol., 135, 305-319.

Neal, C., Reynolds, B., Smith, C.J., Hill, S., Neal, M., Conway, T., Ryland, G.P., Jeffrey, H.A., Robson, A.J. and Fisher, R., 1992b. The impact of conifer harvesting on stream water $\mathrm{pH}$, alkalinity and aluminium concentrations for the British Uplands: an example for an acidic and acid sensitive catchment in midWales. Sci. Tot. Environ., 126, 75-87.

Neal, C., House, W.A., Jarvie, H.P., Leeks, G.J.L. and Marker, A.H., 1997a. Conclusions to the special volume of Science of the Total Environment concerning UK fluxes to the North Sea, Land Ocean Interaction Study: river basins research, the first two years. Sci. Tot. Environ., 194/195, 467-477.

Neal, C., Wilkinson, J., Neal, M., Harrow, M., Wickham, H., Hill, L. and Morfitt, C. 1997b. The hydrochemistry of the River Severn, Plynlimon, mid-Wales. Hydrol. Earth Syst. Sci., 1, 583618.

Neal, C., Reynolds, B., Adamson, J.K., Stevens, P.A., Neal, M., Harrow, M. and Hill, S., 1998a. Analysis of the impacts of major anion variations on surface water acidity particularly with regard to conifer harvesting: case studies from Wales and Northern England. Hydrol. Earth Syst. Sci., 2, 303-322.

Neal, C., Reynolds, B., Wilkinson, J., Hill, T., Neal, M., Hill, S. and Harrow, M., 1998b. The impacts of conifer harvesting on runoff water quality: a regional study for Wales. Hydrol. Earth Syst. Sci., 2, 323-344. 
Neal, C., Reynolds, B., Neal, M., Pugh, B., Hill, L. and Wickham, H.D., 2001. Long-term changes in the water quality of rainfall, cloud water and stream water for moorland, forested and clearfelled catchments at Plynlimon, mid-Wales. Hydrol. Earth Syst. Sci., 5, 459-476.

Webb, B.W., Phillips, J.M. and Walling, D.E., 2000. A new approach to deriving "best estimate" chemical fluxes for rivers draining the LOIS study area. Sci. Tot. Environ., 251/252, 4554.
Whitehead, P.G. and Neal, C., 1987. Modelling the effect of acid deposition in upland Scotland. Trans. Roy. Soc. Edinb.: Earth Sci., 78, 385-392.

Wilkinson, J., Reynolds, B., Neal, C., Hill, S., Neal, M. and Harrow, M. 1997. Major, minor and trace element composition of mist and rainwater at Plynlimon, mid-Wales. Hydrol. Earth Syst. Sci. 1, 557-570. 